American Journal of Applied Sciences 6 (7): 1313-1320, 2009

ISSN 1546-9239

(C) 2009 Science Publications

\title{
Modeling of Nitric Oxide Formation in Single Cylinder Direct Injection Diesel Engine Using Diesel-Water Emulsion
}

\author{
${ }^{1}$ K. Kannan and ${ }^{2} \mathrm{M}$. Udayakumar \\ ${ }^{1}$ Department of Mechanical Engineering, Anjalai Ammal-Mahalingam Engineering College, \\ Kovilvenni TN, India 614403 \\ ${ }^{2}$ Department of Mechanical Engineering, National Institute of Technology, \\ Tiruchirappalli TN, India 620015
}

\begin{abstract}
Problem statement: Water injection into the combustion chamber of diesel engine found to be one of best method for in-cylinder control of NOx formation. Approach: The combustion of waterdiesel emulsion in diesel engine was simulated using a computer program to estimate the heat release rate, cylinder pressure, brake thermal efficiency, brake specific fuel consumption and NO formation. Results: The numerical simulation was performed at different equivalence ratios, engine speeds and water percentages. The numerical simulation was preferred to study the combustion behavior and emission of diesel engine because the experimental investigations were time consuming and costly affair. Conclusion/Recommendations: Experiments also conducted to validate the predicted results of computer simulation. Though the zero dimensional simulation models predicted NO formation during combustion process, the first appearance of NO could not be identified using this method which can be solved by CFD technique.
\end{abstract}

Key words: Diesel engine, emulsion, micro-explosion, heat release rate, nitric oxide emission

\section{INTRODUCTION}

Due to fuel economy advantages of direct injection diesel engines, there are intense research efforts ongoing in the combustion and emission aspects of this type of engine. Nitric Oxide (NO) and soot are the two major pollutants in the diesel engine exhaust. It is known that the simultaneous reduction of $\mathrm{NO}$ and soot is rather difficult due to the opposite influences of several engine design and operating conditions on their formation. The water injection into the combustion chamber of diesel engine found to decrease the NO formation and soot simultaneously.

Numerical study of combustion of emulsified fuel ${ }^{[1-4]}$ revealed that the presence of water vapor in the reactants influences the physical and chemical kinetics of combustion and has beneficial effect on rate of heat release and reduction in pollutant emission. During combustion vaporized water reduces the flame temperature and changes in chemical composition of reactants, resulting higher $\mathrm{OH}$ radicals concentration controlling NO formation rate and soot oxidation ${ }^{[1]}$. The $\mathrm{OH}$ radicals does not combine effectively with molecular nitrogen to form $\mathrm{NO}$ and introduction of water reduces flame temperature which in turn reduces the rate of NO formation ${ }^{[2]}$. From the NO reaction kinetics, it was found that NO emission is inversely proportional to engine speed ${ }^{[3]}$.

Modeling and simulation of diesel engine processes is an important avenue of research. Effective process modeling in diesel engine provides a cost efficient way of studying different engine geometries and operating conditions. Using zero dimensional simulation studies on diesel engine, when operating on diesel-oil emulsion, it was found that NOx emission was reduced by $29-37 \%$ and $\mathrm{HC}$ emission was reduced by $60-90 \%{ }^{[4]}$.

Experimental studies were also conducted in diesel engine using emulsified fuel ${ }^{[5-8,10]}$ to confirm the results of numerical studies. The fuel with a larger emulsion ratio results in a longer ignition delay and a longer premixed combustion phase. Both the maximum rate of pressure rise and the maximum heat release rate increase as combustion occurs more impulsively with the fuel of a larger emulsion ratio. It is necessary to advance the injection timing to compensate for the longer ignition delay and premixed combustion period. The optimum water amount in the emulsified fuel is 20$25 \%$ for minimum NOx and BSFC when the engine is operating at $1400 \mathrm{rpm}^{[5]}$. At all load condition in IDI

Corresponding Author: K. Kannan, Department of Mechanical Engineering, Anjalai Ammal-Mahalingam Engineering College, Kovilvenni TN, India 614403 
diesel engine, the NOx specific emission found decreasing with water injection and the reason being the vaporization and sensible heat of water reduces the local adiabatic flame temperature. When the emulsified fuel is used improvement in specific fuel consumption and thermal efficiency were obtained due to the reduction in heat losses ${ }^{[6,7]}$. It was found that the best performance of the engine with respect to efficiency and NOx and soot emission was found when the engine is operating on emulsified fuel with $20 \%$ water by volume. It was also found that the percentage of water in the emulsion increases, the torque produced increases. This may be attributed to the additional force on the top of the piston provided by the pressure exerted by the steam ${ }^{[7]}$. As the percentage of water in the emulsion increases, a larger amount of diesel is displaced by an equal amount of water. This means that less diesel fuel is actually contained within each volume of the emulsion. So BSFC decreases. The water/oil emulsified fuel increases the brake thermal efficiency of internal combustion engine. The maximum increase in brake thermal efficiency occurs when $20 \%$ water in the emulsion is used and this is due to the fact that the BSFC is at its minimum value. It is found that as the percentage of water in the emulsion increases, the exhaust temperature decreases. The ignition delay increase with water-oil ratio, however, the overall combustion characteristics were found similar to those of diesel fuel ${ }^{[8]}$. From the photographic study, it was found that strong micro-explosion occur in the bottom region of the luminous flames near the spray tip. There are numerous small, round regions due to explosion of superheated water in the droplets. These spherical regions may grow bigger, collapse with new flames or convect with the mean flow motion. There is a range of the sizes, from small ones that are barely identifiable to those of the diameters of a few millimeters. The luminous flames of the diesel fuel are more homogeneous, brighter and yellow in color with no micro-explosion observed. Micro-explosions of a group of droplets of the emulsion fuel are strong enough to eject fragments of torn droplets to expand the tip and angle of the spray, enhancing mixing of fuel with surrounding air for faster and more efficient combustion. The combustion of emulsion droplet is characterized by the micro-explosion, which is caused by the volatility difference between the water and the base fuel ${ }^{[9]}$. Smoke and NOx emissions decrease as the water amount in emulsion is increased. Due to the overall shortening of combustion duration by introducing water into fuel, fuel saving can be achieved if injection timing is optimized. The pressure rise ignition delay increases almost linearly with water content within the range of investigation. The maximum cylinder pressure did not change significantly at the loads of investigation.

Simulation of diesel cycle: Performance and emission of diesel engine depends on the combustion behavior of fuel in the combustion chamber. Experimental investigation of the combustion process in a typical diesel engine is a complex, time consuming and costly affair. Mathematical models have been developed by various researchers to understand combustion and subsequently the performance and formation of pollutants. The various mathematical models proposed are Zero-dimensional (Single Zone) model, Phenomenological (Multi zone) model and Multi dimensional (CFD) models. Zero-dimensional model, based on first law of thermodynamics, is used to analyze performance characteristics and NO emissions of engine in this research study.

In the single zone model, the entire combustion chamber is considered as single zone. The fundamental assumptions for the model are:

- Cylinder charge is homogeneous gas mixture of fuel vapor and air

- Pressure and temperature inside the cylinder are uniform and vary with crank angle

- Specific heats of the gaseous mixture are calculated as a function of temperature

Compression process: Pressure change during compression:

$P_{\theta+1}=P_{\theta}\left(\frac{V_{\theta}}{V_{\theta+1}}\right)^{k_{r}}$

Temperature change during compression:

$\mathrm{T}_{\theta+1}=\mathrm{T}_{\theta}\left(\frac{\mathrm{V}_{\theta}}{\mathrm{V}_{\theta+1}}\right)^{\mathrm{k}_{\mathrm{r}}}$

Ignition delay: Ignition delay time can be calculated as the difference between the time at which combustion starts and the time at which injection starts. Ignition delay is a complicated function of mixture temperature, pressure and equivalence ratio and fuel properties. The correlation proposed by Assanis $^{[15]}$ is used in the model:

$\tau_{\text {id }}=\frac{2.4}{\varphi^{0.2} \mathrm{P}^{1.02}} \exp \left(\frac{\mathrm{Ea}}{\mathrm{RT}}\right)$ 
Heat transfer coefficient: The heat transfer coefficient between cylinder gases and wall is calculated by Hohenberg ${ }^{[16]}$ correlation given as:

$$
\mathrm{h}=\frac{130 \mathrm{P}^{0.8}\left(\mathrm{C}_{\mathrm{m}}+1.4\right)^{0.8}}{\mathrm{~V}^{0.06} \mathrm{~T}^{0.4}}
$$

Combustion process: Heat release rate is calculated using model developed by Watson which is based on the Lyn's description of compression ignition combustion-a rapid premixed burning phase followed by a slower mixing controlled burning phase ${ }^{[13]}$. Algebraic functions are used to describe the premixed heat release phase and mixing controlled heat release phase. Fraction of fuel burn in premixed phase:

$\beta=1-\frac{\mathrm{a} \varphi^{\mathrm{b}}}{\tau_{\mathrm{id}}{ }^{\mathrm{c}}}$

where, a, b, c are constants:

$0.8<\mathrm{a}<0.95 ; 0.25<\mathrm{b}<0.45 ; 0.025<\mathrm{c}<0.5$

The premixed burning function:

$f_{1}=1-\left(1-X^{k 1}\right)^{k 2}$

The mixing controlled function:

$\mathrm{f}_{2}=1-\exp \left(-\mathrm{k}_{3} \mathrm{X}^{\mathrm{k} 4}\right)$

Where:

$\mathrm{X}=\frac{\mathrm{t}-\mathrm{t}_{\text {ign }}}{\Delta \mathrm{t}_{\text {comb }}}$

$\mathrm{k}_{1}=2+1.25 \times 10^{-8}\left(\tau_{\text {id }} \mathrm{N}\right)^{2.4}$

$\mathrm{k}_{2}=5000$

$\mathrm{k}_{3}=\frac{14.2}{\varphi^{0.644}}$

$\mathrm{k}_{4}=0.79 \mathrm{k}_{3}^{0.25}$

The mass of fuel burned:

$$
\frac{\mathrm{m}_{\mathrm{fb}} \mathrm{X}}{\mathrm{m}_{\mathrm{fo}}}=\beta \mathrm{f}_{1}+(1-\beta) \mathrm{f}_{2} \mathrm{~kg} \mathrm{CA}^{-1}
$$

Heat release rate:
$\frac{\mathrm{dQ}_{\mathrm{c}}}{\mathrm{d} \theta}=\mathrm{Q}_{\mathrm{LHV}} \frac{\mathrm{dm}_{\mathrm{fb}}}{\mathrm{d} \theta}$

Rate of heat transfer:

$\frac{\mathrm{dQ}_{\mathrm{h}}}{\mathrm{d} \theta}=\mathrm{hA}_{\theta}\left(\mathrm{T}_{\theta}-\mathrm{T}_{\mathrm{w}}\right)$

Rate of Work transfer:

$\frac{\mathrm{dW}}{\mathrm{d} \theta}=\mathrm{P} \frac{\mathrm{dV}}{\mathrm{d} \theta}$

The energy Equation for the closed cycle period can be written as:

$\mathrm{m} \frac{\mathrm{du}}{\mathrm{d} \theta}=\frac{\mathrm{dQ}_{\mathrm{c}}}{\mathrm{d} \theta}-\frac{\mathrm{dQ}_{\mathrm{h}}}{\mathrm{d} \theta}-\frac{\mathrm{dW}}{\mathrm{d} \theta}$

or

$\frac{\mathrm{dT}}{\mathrm{d} \theta}=\frac{1}{\mathrm{mC}_{\mathrm{v}}} \frac{\mathrm{dQ}_{\mathrm{c}}}{\mathrm{d} \theta}-\frac{\mathrm{hA}_{\theta}\left(\mathrm{T}_{\theta}-\mathrm{T}_{\mathrm{w}}\right)}{\mathrm{mC}_{\mathrm{v}}}-\frac{\mathrm{RT}}{\mathrm{C}_{\mathrm{v}}} \frac{1}{\mathrm{~V}} \frac{\mathrm{dV}}{\mathrm{d} \theta}$

The equation is solved by Runge-Kutta method ${ }^{[14]}$ to determine the temperature at different crank angle during combustion. Knowing the temperature at every crank angle, the pressure at each crank angle can also be determined by the relation:

$\mathrm{P}=\frac{\mathrm{mRT}}{\mathrm{V}}$

Expansion process: Temperature change during expansion process:

$$
\mathrm{T}_{\theta+1}=\mathrm{T}_{\theta}\left(\frac{\mathrm{V}_{\theta+1}}{\mathrm{~V}_{\theta}}\right)^{\mathrm{k}_{\mathrm{p}}-1}
$$

Pressure change during expansion process:

$$
P_{\theta+1}=P_{\theta}\left(\frac{T_{\theta+1}}{T_{\theta}}\right)^{\frac{k_{p}}{k_{p}-1}}
$$

Gas exchange process: The pressure change during the exhaust process is given by:

$$
\frac{\mathrm{dP}}{\mathrm{d} \theta}=\mathrm{k}_{\mathrm{p}} \mathrm{P}\left(\frac{1}{\mathrm{M}} \frac{\mathrm{dM}}{\mathrm{d} \theta}-\frac{1 \mathrm{dV}}{\mathrm{V}} \frac{\mathrm{d} \theta}{\mathrm{d} \theta}\right)
$$


The pressure change during the intake process is written as:

$$
\frac{d P}{d \theta}=k_{r}\left(\frac{R_{a}}{V} \frac{d M}{d \theta}-\frac{P}{V} \frac{d V}{d \theta}\right)
$$

Simulation of NOx formation: Nitrogen oxides are abbreviated by the symbol NOx and comprise both nitric oxide (NO) and nitrogen dioxide $\left(\mathrm{NO}_{2}\right)$. Nitric oxide is generated in combustion processes under the influence of high gas temperatures and a sufficient local oxygen. Diesel fuel contains only a very small amount of nitrogen, so NO formation occurs almost exclusively through the oxidation of atmospheric nitrogen. A major hurdle in understanding the mechanism of formation and controlling its emission is that combustion is highly heterogeneous and transient in diesel engines. While $\mathrm{NO}$ and $\mathrm{NO}_{2}$ are lumped together as $\mathrm{NOx}$, there are some distinctive differences between these pollutants. NO is a colorless and odorless gas, while $\mathrm{NO}_{2}$ is a reddish brown gas with pungent odor. Both gases are considered toxic, but $\mathrm{NO}_{2}$ has a level of toxicity 5 times greater than that of NO. Although $\mathrm{NO}_{2}$ is largely formed from oxidation of NO, attention has been given on how NO can be controlled before and after combustion ${ }^{[11]}$.

Four different mechanisms lead to the formation of nitric oxide in combustion system.

The thermal NO is formed at high temperatures under slightly lean conditions with the burned products. The involved nitrogen and oxygen stem from the combustion air.

The prompt NO, path describes the reaction of $\mathrm{N}_{2}$ from combustion air with hydrocarbon radicals in fuelrich regions. Because of the need of hydrocarbon radicals, this path is followed directly within the reaction zone.

The fuel NO which refers to the formation of NO from fuel bound nitrogen as it may be contained in coal and heavy distillates of petroleum.

$\mathrm{N}_{2} \mathrm{O}$ intermediate route is activated at lower temperature than the thermal NO in a fuel-lean and high pressure environment. It can become important in gas turbine combustion, but it has only a minor effect in diesel engine combustion.

$\mathrm{NO}$ is formed during the post flame combustion process in a high temperature region. The most widely accepted mechanism was suggested by Zeldovich ${ }^{[13]}$. The principal source of NO formation is the oxidation of the nitrogen present in atmospheric air. The nitric oxide formation chain reactions are initiated by atomic oxygen which forms from the dissociation of oxygen molecules at the high temperature reached during the combustion process:
$\mathrm{N}_{2}+\mathrm{O} \rightarrow \mathrm{NO}+\mathrm{N}$

$\mathrm{N}+\mathrm{O}_{2} \rightarrow \mathrm{NO}+\mathrm{O}$

$\mathrm{N}+\mathrm{OH} \rightarrow \mathrm{NO}+\mathrm{H}$

The initial NO formation rate $\left(\mathrm{KmoL} \mathrm{m}^{-3} \mathrm{sec}\right)$ is given as:

$\frac{\mathrm{d}[\mathrm{NO}]}{\mathrm{dt}}=\frac{6 \times 10^{16}}{\mathrm{~T}^{0.5}} \exp \left(\frac{-69090}{\mathrm{~T}}\right)\left[\mathrm{O}_{2}\right]_{\mathrm{e}}^{0.5}\left[\mathrm{~N}_{2}\right]_{\mathrm{e}}$

NO formation is strong dependent on temperature and oxygen concentration during the combustion phase. Chemical equilibrium consideration indicates that for burnt gases at typical flame temperatures, $\mathrm{NO}_{2} / \mathrm{NO}$ ratios should be negligible small. While experimental data shows that this is true for spark ignition engines, in diesels, $\mathrm{NO}_{2}$ can be $10-30 \%$ of total exhaust emissions of oxides of nitrogen. NO formed in the flame zones can be rapidly converted to $\mathrm{NO}_{2}$ via reactions such as:

$\mathrm{NO}+\mathrm{HO}_{2} \rightarrow \mathrm{NO}_{2}+\mathrm{OH}$ via:

Subsequently, conversion of this $\mathrm{NO}_{2}$ to $\mathrm{NO}$ occurs

$\mathrm{NO}_{2}+\mathrm{O} \rightarrow \mathrm{NO}+\mathrm{O}_{2}$

Unless the $\mathrm{NO}_{2}$ formed in the flame is quenched by mixing with cooler fluid. This explanation is consistent with the highest $\mathrm{NO}_{2} \mathrm{NO}^{-1}$ ratio occurring at light loads in diesels, when cooler regions which could quench the conversion back to NO are widespread. The NO formation in diesel combustion is mainly governed by thermal NO described by the extended Zeldovich mechanism. The NO that was generated through thermal NO accounted for $88 \%$ of total NO. Fenimore $\mathrm{NO}$ and $\mathrm{NO}$ via $\mathrm{N}_{2} \mathrm{O}$ accounted for 7 and $1.5 \%$ respectively ${ }^{[12]}$.

\section{MATERIALS AND METHODS}

Based on the model description, a computer program is developed using $\mathrm{C}$ program for the diesel cycle simulation to predict the cylinder pressure for the complete cycle and performance parameters such as brake power, brake specific fuel consumption and brake thermal efficiency and NO formation during combustion process using Zeldovich mechanism. The specifications of the engine used for the simulation and experimental studies are shown in the Table 1. 
The engine is equipped with crank angle sensor, cylinder pressure sensor, thermocouples to measure the temperature of water, air and gas, rotameter to measure the water flow rate and manometer to measure air flow and fuel flow. All the measured readings are fed to computer using a 12 bit add on card to analyze the results. An Engine performance analysis software "Engine soft" is used to analyze and plot the graphs. The exhaust gas analyzer, Model QRO 402, is used to measure $\mathrm{CO}, \mathrm{HC}, \mathrm{CO}_{2}, \mathrm{O}_{2}$ and $\mathrm{NOx}$ emissions.

\section{RESULTS}

The computer program was run for the engine specifications shown in the Table 1 at different equivalence ratios $(0.95,0.9,0.85$ and 0.8$)$, at different engine speeds (1400, 1500 and $1600 \mathrm{rpm})$ and at different water in percentage $(0,10$ and $20 \%)$ in the diesel-water emulsion to estimate heat release rate, cylinder pressure, specific fuel consumption, brake thermal efficiency and Nitric oxide formation during combustion. The experiments were conducted on the

Table 1: Engine specifications

\begin{tabular}{ll}
\hline Bore & $87.5(\mathrm{~mm})$ \\
Stroke & $110(\mathrm{~mm})$ \\
Connecting rod length & $234(\mathrm{~mm})$ \\
Speed & $1500(\mathrm{rpm})$ \\
Compression ratio & 17.5 \\
Swept volume & $661(\mathrm{cc})$ \\
Loading & Eddy current dynamometer \\
Inlet valve open & $5^{\circ} \mathrm{bTDC}$ \\
Inlet valve close & $36^{\circ} \mathrm{aBDC}$ \\
Exhaust valve open & $36^{\circ} \mathrm{bBDC}$ \\
Exhaust valve close & $5^{\circ}$ aTDC \\
Fuel injection & $23^{\circ} \mathrm{bTDC}$ \\
\hline
\end{tabular}

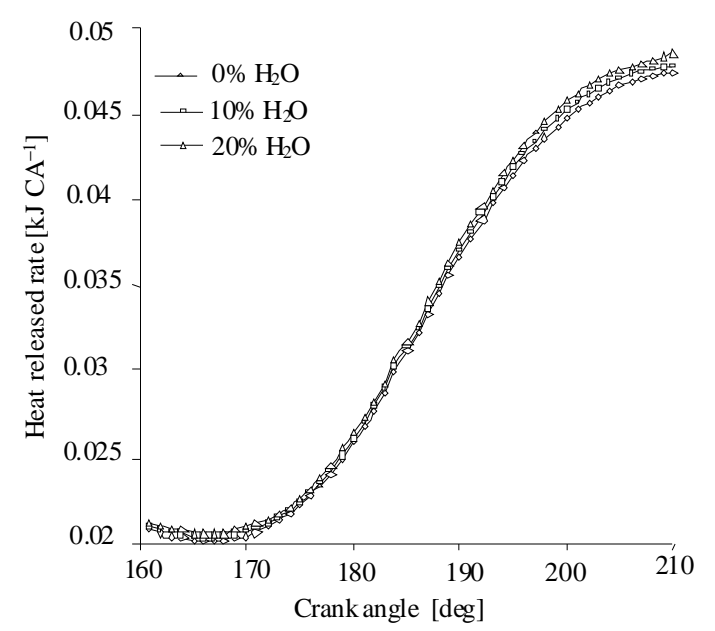

Fig. 1: Heat release rate $[\mathrm{N}=1500 \mathrm{rpm}, \mathrm{CR}=17.5$, $\Phi=0.85]$ same engine under certain operating conditions to validate the simulated readings. All the results were shown in Fig. 1-9.

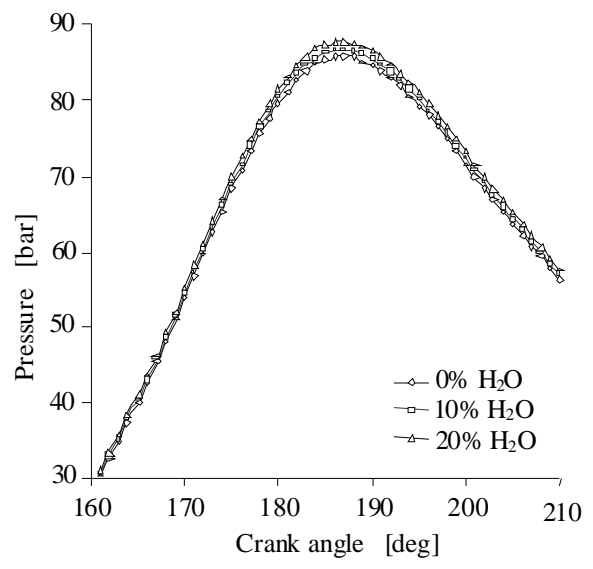

Fig. 2: Pressure rise during combustion $[\mathrm{N}=1500 \mathrm{rpm}$, $\mathrm{CR}=17.5, \Phi=0.85]$

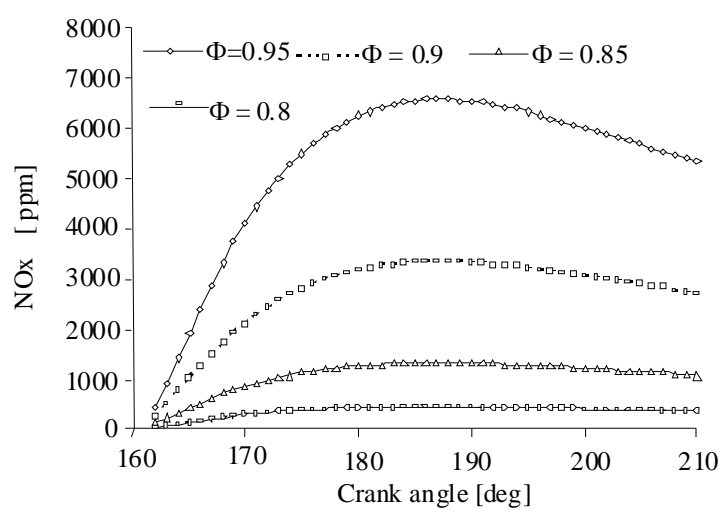

Fig. 3: NO formation at various equivalence ratios $[\mathrm{N}=1500 \mathrm{rpm}, \mathrm{CR}=17.5, \Phi=0.85]$

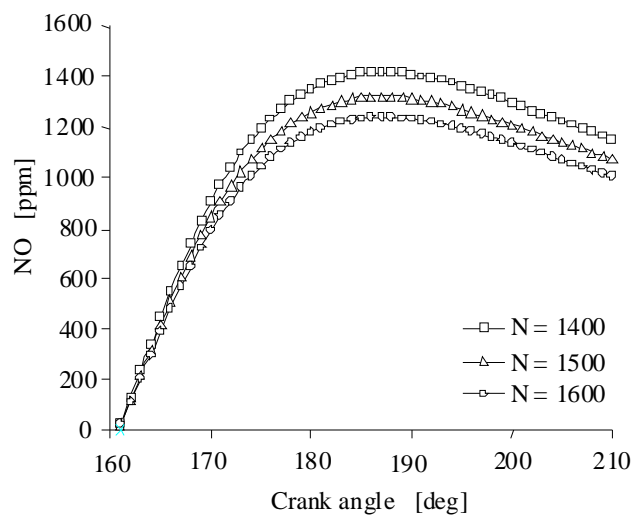

Fig. 4: NO formation at various engine speeds $[\mathrm{CR}=$ $17.5, \Phi=0.85]$ 


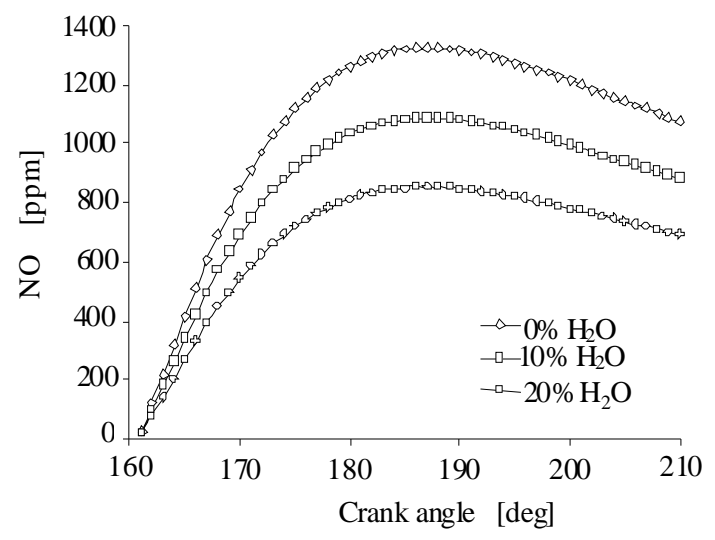

Fig. 5: $\mathrm{NO}$ formation at various percentage of $\mathrm{H}_{2} \mathrm{O}$ $[\mathrm{N}=1500 \mathrm{rpm}, \mathrm{CR}=17.5, \Phi=0.85]$

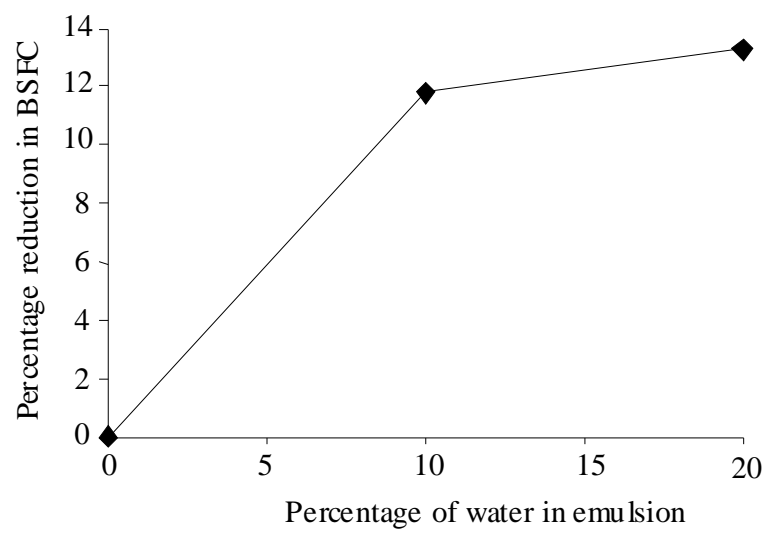

Fig. 6: Effect on brake specific fuel consumption [ $\mathrm{N}=$ $1500 \mathrm{rpm}, \mathrm{CR}=17.5, \Phi=0.85$ ]

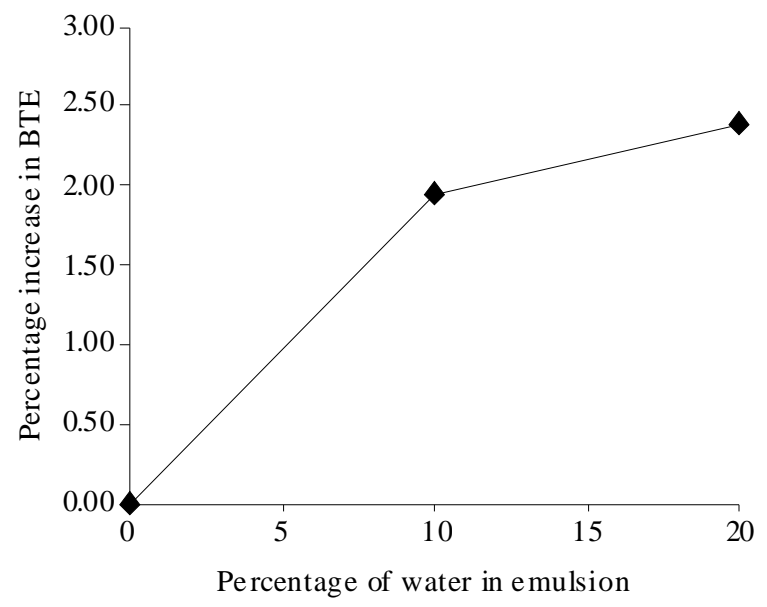

Fig. 7: Effect on brake thermal efficiency [ $\mathrm{N}=1500$ $\mathrm{rpm}, \mathrm{CR}=17.5, \Phi=0.85]$

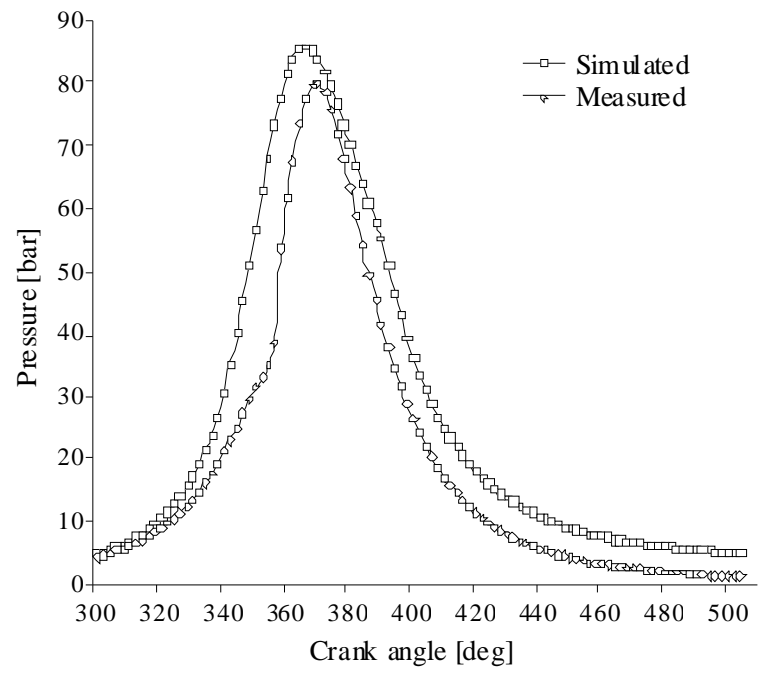

Fig. 8: Simulated and measured cylinder pressure [N $=1500 \mathrm{rpm}, \mathrm{CR}=17.5, \Phi=0.85]$

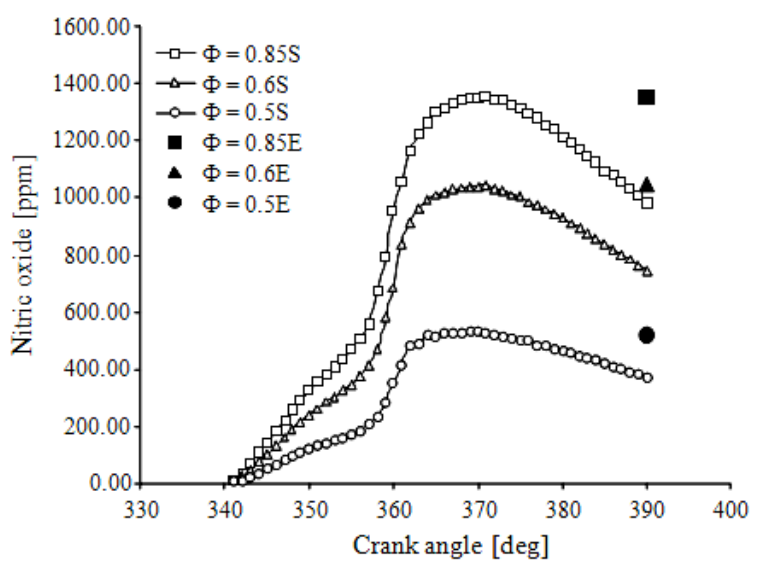

Fig. 9: Simulated and measured NOx emission (S: Simulated values, E: Experimental value)

\section{DISCUSSION}

Effect of emulsified fuel on heat release rate and pressure rise: The rate of heat release and pressure rise were estimated at engine operating conditions of constant compression ratio, constant speed and constant equivalence ratio. The rate of heat release for 0,10 and $20 \%$ water in the emulsion is shown in Fig. 1. The rate of heat release found to increase with percentage of water. The reason seems to be the fact that the mixture is better prepared due to prolonged ignition delay. Experimental investigations ${ }^{[8]}$ shows that strong microexplosions of a group of droplets can occur in the specific regions of the luminous flame near the spray 
tip. Micro-explosions of the emulsion fuel seem to enhance the mixing of fuel with surrounding air for faster and more efficient combustion also resulting in a higher heat release rate.

The pressure rise during combustion for 0,10 and $20 \%$ water in the emulsion is shown in Fig. 2. The cylinder pressure is increasing with the percentage of water in the emulsion.

Effect of equivalence ratio on NO formation: The NO formation during the combustion is simulated using Zeldovich mechanism, the variation of NO formation with equivalence ratio is shown in Fig. 3 at constant engine speed and compression ratio for diesel combustion. The rate of NO formation is increasing with equivalence ratio as the mass of fuel injected is increasing which gives higher flame temperature.

Effect of engine speed on NO formation: The NO formation with engine speed is shown in Fig. 4, under similar engine operating conditions, constant compression ratio and equivalence ratio, the NO rate is decreasing with engine speed which is similar to the results obtained by Takemi Chikahisa et al. ${ }^{[3]}$.

Effect of water percentage in the emulsion on NO formation: Figure 5 shows the NO formation rate with percentage of water in the emulsion. The vaporization and sensible water heats reduces the local adiabatic temperature and thus NO formation. From the simulated results, it is found that 18 and $21.5 \%$ of reduction in NO is achieved with 10 and $20 \%$ dilution of diesel with water respectively.

Effect of emulsified fuel on engine performance and NOx emission: The effect of water in the emulsion on brake specific fuel consumption and brake thermal efficiency are shown in Fig. 6 and 7 respectively. The percentage of water in the emulsion increases, the brake specific fuel consumption decreases considering diesel alone as total fuel ${ }^{[7]}$.

The brake thermal efficiency is increasing with the water percentage in the emulsion increases. Abu-Zaid ${ }^{[7]}$ also reported that the average increase in brake thermal efficiency for $20 \%$ water emulsion is approximately $3.5 \%$ over the use of diesel for the engine speed range studied. Jamil Ghojel et $a l^{[4]}$ found that the brake thermal efficiency for Diesel Oil Emulsion (DOE) is higher over the test range in the direct injection diesel engine.

The predicted and measured cylinder pressure at different crank angles between inlet valves closing to exhaust valve opening is shown in Fig. 8. It can be seen that the zero dimensional model predicts a higher values of pressure at different crank angles. In this model, the cylinder temperature and equivalence ratio are assumed to be uniform throughout the cylinder. Though the Watson's heat release model can handle the premixed and diffusive models of combustion, the heat transfer by radiation is not considered in this model. Because of this simplification, the predicted pressures are higher than the measured values.

The predicted NO values at various equivalence ratios at different crank angles during combustion phase in the cycle and measured NOx at engine outlet are shown in Fig. 9. The model underestimates the NO emission because only thermal mechanism is considered for NO formations in the model and it is very difficult to correctly model thermal NO level due to the simplified analysis used for NO formation. However, the measured NOx emission is agreeable with the predicted results.

\section{CONCLUSION}

The single zone zero dimensional model for direct injection diesel engine for complete cycle including NO formation during combustion process has been successfully developed for water-diesel emulsion combustion. The model is effectively used to estimate the performance parameters and NO emission for water-diesel combustion at various water percentage in the emulsion, equivalence ratio, compression ratio and speed. The NO emission prediction at different equivalence ratio agree with the experimental results. Though the single zone model predicts the NO, the first appearance of NO during combustion could not be identified using the simulation. A CFD studies on combustion and emission of diesel engine using Fluent is under progress to fulfill the above needs.

\section{REFERENCES}

1. Niko, S., B. Kegl and R.W. Dibble, 2002. Numerical and experimental study of water/oil emulsified fuel combustion in a diesel engine. Fuel, 81: 2035-2044. DOI: 10.1016/S00162361(02)00135-7

2. Mello, J.P. and A.M. Mellor,1999. NOx emissions from direct injection diesel engines with water/steam dilution. SAE. Trans., 108: 366-380. http://direct.bl.uk/bld/PlaceOrder.do?UIN=086485 $163 \&$ ETOC $=$ RN\& from $=$ searchengine

3. Chikashisa, T., M. Konno, T. Murauama and T. Kumagai, 1994. Analysis of NO formation characteristics and its control concepts in diesel engines from NO reaction kinetics. JSAE. Rev., 15: 297-303.

https://shop.sae.org/technical/papers/950215 
4. Ghojel, J., D. Honnery and K. Al-Khaleefi, 2006. Performance, emissions and heat release characteristics of direct injection diesel engine operating of diesel oil emulsion. Applied Thermal Eng., 26: 2132-2141. http://cat.inist.fr/?aModele $=$ afficheN $\&$ cpsidt $=18023088$

5. Park, J.W., K.Y. Huh and J.H. Lee, 2001. Reduction of NOx, smoke and brake specific fuel consumption with optimal injection timing and emulsion ratio of water-emulsified diesel. Proc. Inst. Mech. Eng., 215: 83-93. DOI: 10.1243/0954407011525476

6. Armas, O., R. Ballesteros, F.J. Martos and J.R. Agudelo, 2005. Characterization of light duty diesel engine pollutant emissions using water-emulsified fuel. Fuel, 84: 1011-1018. http://cat.inist.fr/?aModele $=$ afficheN\&cpsidt $=16576853$

7. Abu-Zaid, M., 2004. Performance of single cylinder, direct injection diesel engine using water fuel emulsions. Energ. Conver. Manage., 45: 697-705. http://cat.inist.fr/?aModele $=$ afficheN\&cpsidt $=15488155$

8. Park, J.W., K.Y. Huh and K.H. Park, 2000. Experimental study on the combustion characteristics of emulsified diesel in arapid compression and expansion machine. Proc. Inst. Mech. Eng., 214: 579-585. http://cat.inist.fr/?aModele $=$ afficheN\&cpsidt $=1456927$

9. Tran, X.T. and J.I. Ghojel, 2005. Impact of introducing water into the combustion chamber of diesel engines on emissions-an overview. Proceedings of the 5th Aisa-Pasific Conference of Combustion, July 17-20, University of Adelaide, Adelaide, Australia, pp: 233-236.

10. Bertrand, D.H., 1986. Combustion of water-indiesel emulsion in an experimental medium speed diesel engine. SAE 860300. http://www.sae.org/technical/papers/860300
11. Avinash, K.A., S.K. Singh, S. Sinha and M.K. Shukla, 2004. Effect of EGR on the exhaust gas temperature and exhaust opacity in compression ignition engine. Sadhana, 29: 275-284. http://www.ias.ac.in/sadhana/Pdf2004Jun/Pe1131.pdf

12. Jin, K. and Y. Daisho, 2003. Simulating combustion and exhaust gas emissions in a DI diesel engine by using a CFD combined with detailed chemistry. J. KONES. Int. Combust. Eng., 10: $1-2$. http://www.ilot.edu.pl/Journal\%20of\%20KONES $\% 202003 \% 20$ No\%203_4/1-2/18.pdf

13. John, B.H., 1988. Internal Combustion Engine Fundamentals. McGraw Hill International 1st Edn., ISBN: 9780070286375, pp: 779.

14. Ganesan, V., 2000. Computer Simulation of Compression Ignition Engine Processes. University Press, ISBN: 8173712932, pp: 248.

15. Dennis, N.A., S.F. Zoran, S.B. Fiveland and M. Syrimis, 2003. A predictive ignition delay correlation under steady-state and transient operation of a direct injection diesel engine. J. Eng. Gas Turbines Power, 125: 401-611. http://cat.inist.fr/?aModele $=$ afficheN\&cpsidt $=14816703$

16. Gunter, F.H., 1979. Advanced approaches for heat transfer calculations. SAE 790825, 2788-2806. https://shop.sae.org/technical/papers/790825 